\title{
An Approach to Risk Isolation for Relatively Low-incidence Conditions: An Australian National Model of Oral Cellulitis
}

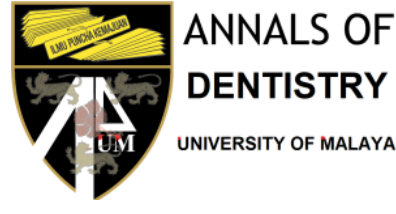

www.adum.edu.my

Ann Dent UM 2019, 26:15-21 Dol: 10.22452/adum.vol26no3

\author{
Abed Aktam Anjrini ${ }^{*}$, Estie Kruger, Marc Tennant
}

KEYWORDS

Oral cellulitis, Australian population, poverty, socioeconomics, untreated dental caries

\begin{abstract}
The purpose of this study was to develop a risk indicator applicable on a national level, to isolate at relatively highresolution, regions where oral cellulitis risk is high. The method used ten years of Western Australian (1999 to 2008) hospitalisation data, and applying the admission risks gleaned from this database (poverty, socioeconomics, age and Indigenous status) to model across Australia (at SA1 level) the risk profile. Five levels of oral cellulitis risk (low to very high) were mapped to each of the 54,000 SA1s that makeup Australia. Cumulative percentage analysis was used to study the effect of distance from capital city of each state on the number of population at high risk. Highest risk category (category 5) SA1s were not equally distributed amongst States, with the Northern Territory having $12.2 \%$ of its population (26011) belonging to category 5 (very high risk). The majority of that population (87.8\%) live more than $100 \mathrm{~km}$ away from the capital city, Darwin. A general trend amongst Australian capital cities was the low number of population at high risk within $5 \mathrm{~km}$ from General Post Office (GPO).
\end{abstract}

\section{INTRODUCTION}

The isolation of risk to specific geographic areas is an important tool for prevention and management of sporadic conditions, as those conditions usually occur in small numbers and tend to follow non-predictable patterns $[1,2]$. One common strategy for such risk isolation has been to statistically analyse multiple geographic variables [2]. However, it could be challenging to establish such a model in conditions where geographic variables (e.g. altitude, weather or distance from the sea) pose little or no effect.

International Research Collaborative - Oral Health and Equity, School of Human Sciences, University of Western Australia, 35 Stirling Hwy Nedlands 6009 Australia.

*Correspondence: Abed.Anjrini@Outlook.com
Oral cellulitis is a rare, sporadic and potentially fatal condition which is predominately a complication risk of untreated dental caries [3-7]. In the Australian context, oral cellulitis is closely related to poverty, age and Indigenous status [7]. The majority of the Australian population live in the major cities (Melbourne, Sydney, Brisbane, Adelaide, Perth, Hobart, Canberra and Darwin) [8], however, people who live in regional and rural areas have higher rates of dental caries [9]. Oral cellulitis could be used as an indicator of the level of oral health in a society. The purpose of this study was to develop a risk indicator applicable on a national level, to isolate at relatively high resolution in Australia, regions where oral cellulitis risk is high. The distribution of the population at risk of oral cellulitis will be studied with the effect 
of distance from the centre of the capital city of each state.

\section{METHODS}

\section{Baseline Risk Analysis}

Ethics approval for this study was obtained from the Ethics Committee of the University of Western Australia, (approval number RA/4/1/5502). Data used were from the Western Australian Hospital Morbidity Data System (HMDS) [10]. It contained every episode of discharge from hospitals for cellulitis of the mouth and submandibular region as the principal oral condition (K12.2), as classified by the International Classification of Diseases-Tenth Australian Modification (ICD-10AM) [11]. The data included the age of patients, as well as the place of residence at time of hospitalisation and Indigenous status. The data obtained were for a period of 10 years, from July 1999 to June 2009. Population data obtained from the Australian Bureau of Statistics 2006 Census were used to calculate the rates for Western Australian Hospitalisations, as this was the near midpoint population data for the hospitalisation data.

The risk indicators used were age, Indigenous status and Socio-Economic Indexes for Areas (SEIFA) quintiles, as these variables are closely associated with oral cellulitis [7]. SEIFA is a coding system that categorizes all Australia into quintiles of socioeconomic status: most disadvantaged, above average disadvantaged, average disadvantaged, below average disadvantaged and least disadvantaged. The first two quintiles have been used in this study, as previous research have shown the first group to be 30 times more affected by oral cellulitis as opposed to more advantaged groups [7]. The three less disadvantaged quintiles (3, 4 and 5) have been combined into one single group as they account for a significant number of cases, (but a low incidence per 100,000 , as the majority of the Australian population belong to those three categories). Six sub-sets of age groups were used for this study: 0-4, 5-14, 15-19, 20-34, 35-49 and 50-69 years, based on previous study methodology [12]. Indigenous status (yes or no) was the final risk variable. A total of 36 distinct rates (cases per 100,000 people) of oral cellulitis were computed using Statistical Package for the Social Sciences v21 (SPSS Inc; www.spss.com) dependent on the mix of the variables sub-sets (SEIFA $(n=3)$, Age $(n=6)$ and Indigenous status $(n=2)$

\section{National modelling}

The Australian Statistical Geography Standard (ASGS) divides Australia into SA1 regions as the smallest nonoverlapping, non-gap statistical cover of Australia. This system commenced in 2011 as the basis of the census data. The modelling of relative risk computed in this study was completed using these geographic and population data (ABS 2011). SA1s generally have a population of 200 to 800 persons, and an average population of about 400 persons. Each SA1 has complete data on age groups, SEIFA groups and Indigenous status, as per the national census.

Using Excel v2003 (Microsoft; Redmond, WA, USA), the risk for each population subset derived from the Western Australian morbidity data was applied across Australia to the appropriate population subset (age, SEIFA and Indigenous status) within each SA1 as outlined by the Australian Bureau of Statistics. A total of 17.4 million Australians (about $80.1 \%$ ) had a risk index under 0.1 and they were then excluded from the risk mapping (a total of 44695 SA1s) as having a minimal or insignificant risk. The remaining 20\% (approximately 4 million people) have been categorised into 5 equal sized (on population) categories: highest risk $20 \%$ of population (very high risk), second $20 \%$ at risk (high risk), third 20\% (moderate risk), fourth 20\% (low risk) and last 20\% (very low risk).

The integrated database was then geo-coded using QGIS (version 2.14) to allow the visualisation of the fully integrated data model all over Australia. This methodology has been previously used for other conditions [12]. A comparison between population at risk was further made using Excel, according to each State and Territory. Using QGIS, SA1s corresponding to the highest risk categories (High risk and very High risk) (using centroids) within $100 \mathrm{~km}$ from the GPO (General Post office) of each capital centre of each Australian State/Territory (Sydney, Melbourne, Brisbane, Perth, Adelaide Canberra, Darwin and Hobart) were selected for further analysis. Those SA1 units were then further separated into bands according to their distance from the GPO. The selected bands were 0-2, 2-5, 5-10, 10-20, 20-40, 40$60,60-80,80-100 \mathrm{~km}$ distance from GPO. All SA1s 
(centroids) in the selected bands were exported into Excel for cumulative percentage analysis

\section{RESULTS}

The national Risk Locator Indicator (RLI) for oral cellulitis was mapped for Australia (Figure 1), with category 1 (very low risk) as light yellow, category 2 (low risk) as orange, category 3 (moderate risk) as dark orange, category 4 (high risk) as red and category 5 (very high risk) as dark red.

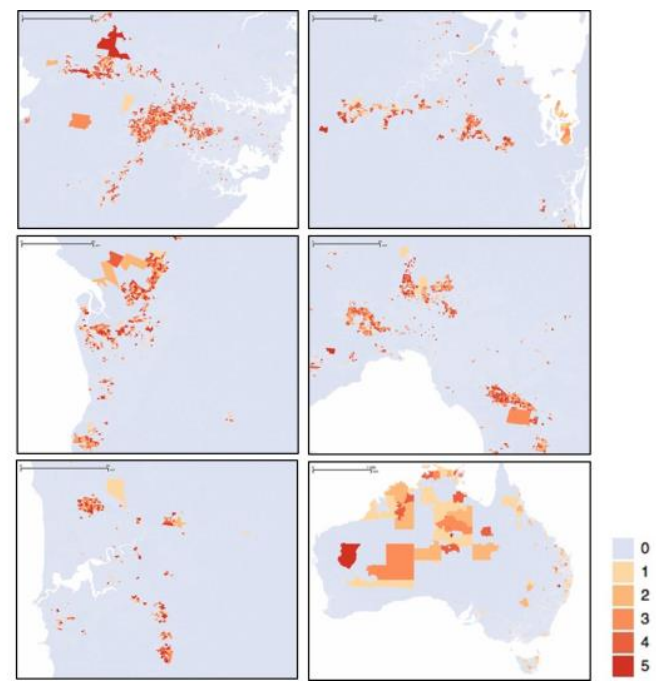

Figure 1. Relative risk index for Sydney (top left), Brisbane (top right), Adelaide (middle left), Melbourne (middle right), Perth (bottom left) and Australia (bottom right). Colours: Category 0 (insignificant risk) as grey, category 1 (very low risk) as light yellow, category 2 (low risk) as orange, category 3 (moderate risk) as dark orange, category 4 (high risk) as red and category 5 (very high risk) as dark red.

The number of the population at risk of oral cellulitis, by State and Territory, for the 5 categories of risk is shown in Table 1, and in Table 2 for Australia and for the $100 \mathrm{~km}$ buffer zones around the capital cities, respectively. The population belonging to the highest risk category (category 5) was not equally distributed amongst States and Territories, with the Northern Territory having $12.2 \%$ of its population (26011) belonging to category 5 (very high risk).

The majority of that population (87.8\%) live more than $100 \mathrm{~km}$ away from the capital city, Darwin. The cumulative percentage of population affected by oral cellulitis risk categories 4 and 5 (high risk and very high risk) for the selected bands of distance from GPO of capital cities (0-2, 2-5, 5-10, 10-20, 20-40, 40-60, 60-80, 80-100 km) is reported in Table 3 and Figure 2.

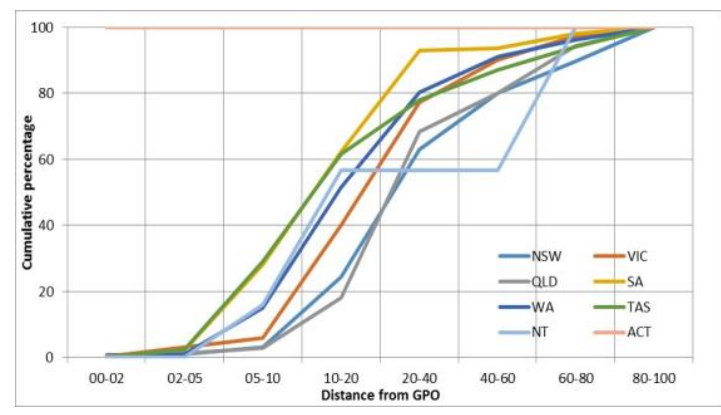

Figure 2. Cumulative percentage of population belonging to risk categories 4 and 5 (high risk and very high risk) according to distance for all states and territories in Australia by distance from GPO.

A general trend amongst Australian capital cities was the low trend of risk within $5 \mathrm{~km}$ from GPO. This continues to be the case until $10 \mathrm{~km}$ for Brisbane, Melbourne and Sydney, with a similar gradual increase of percentage of population at risk after 10 $\mathrm{km}$ for those 3 cities. For Hobart, Adelaide and Perth, the percentage of population at risk increases gradually from the 5-km band. Darwin, however, has a specific plateau between $20 \mathrm{~km}$ and $60 \mathrm{~km}$, followed by a very high-risk band between 60 and $80 \mathrm{~km}$ (accounting for $44 \%$ of whole population at risk).

\section{DISCUSSION}

This research has established a geographic risk indicator of oral cellulitis in Australia. The method relied upon analysing hospitalisation data for 10 years in Western Australia, identifying the strongest risk indicators (poverty categories SEIFA, age and Indigenous status based on admission trends) and applying these at a small area level across the total population of Australia. 
Table 1. Oral cellulitis risk in Australia by population (groups 0 to 5 : insignificant risk, very low risk, low risk, moderate risk, high risk and very high risk) by States and Territories: NSW: New south Wales, VIC: Victoria, QLD: Queensland, SA: South Australia, WA; Western Australia, (Northern Territory (Darwin), TAS: Tasmania, ACT: Australian Capital territory.

\begin{tabular}{|cccccccc|}
\hline & \multicolumn{7}{c|}{ Risk category } \\
\cline { 2 - 6 } State & $\mathbf{0}$ & $\mathbf{1}$ & $\mathbf{2}$ & $\mathbf{3}$ & $\mathbf{4}$ & $\mathbf{5}$ & Grand Total \\
\hline NSW & 5460726 & 293243 & 283720 & 295178 & 301260 & 283529 & 6917656 \\
\hline VIC & 4434819 & 167307 & 191516 & 184997 & 184417 & 190983 & 5354039 \\
\hline QLD & 3510942 & 181599 & 170765 & 163751 & 153109 & 152571 & 4332737 \\
\hline SA & 1198142 & 76248 & 70634 & 73637 & 88067 & 89841 & 1596569 \\
\hline WA & 1989053 & 41781 & 52258 & 50676 & 51997 & 53406 & 2239171 \\
\hline TAS & 327818 & 44739 & 40430 & 38431 & 26856 & 17077 & 495351 \\
\hline NT & 158395 & 8555 & 4618 & 6018 & 8346 & 26011 & 211943 \\
\hline ACT & 354431 & 819 & 365 & 304 & 809 & 490 & 357218 \\
\hline Grand Total & 17434326 & 814291 & 814306 & 812992 & 814861 & 813908 & 21504684 \\
\hline
\end{tabular}

Table 2. Oral cellulitis risk within $100 \mathrm{~km}$ from capital cities by population (groups 0 to 5 : insignificant risk, very low risk, low risk, moderate risk, high risk and very high risk) by States and Territories: NSW: New south Wales (Sydney), VIC: Victoria (Melbourne), QLD: Queensland(Brisbane), SA: South Australia(Adelaide), WA; Western Australia(Perth), TAS: Tasmania(Hobart), (Northern Territory (Darwin), ACT: Australian Capital Territory (Canberra).

\begin{tabular}{|cccccccc|}
\hline & \multicolumn{7}{c|}{ Risk category } \\
\cline { 2 - 7 } State & $\mathbf{0}$ & $\mathbf{1}$ & $\mathbf{2}$ & $\mathbf{3}$ & $\mathbf{4}$ & $\mathbf{5}$ & Grand Total \\
\hline NSW & 4264672 & 111033 & 135322 & 170705 & 216446 & 228244 & 5126422 \\
\hline VIC & 3748343 & 82357 & 118941 & 130032 & 135819 & 157049 & 4372541 \\
\hline QLD & 2474732 & 65207 & 63684 & 74423 & 89034 & 99099 & 2866179 \\
\hline SA & 1038148 & 48266 & 50074 & 55873 & 71970 & 78467 & 1342798 \\
\hline WA & 1609977 & 18067 & 27334 & 32554 & 31767 & 39839 & 1759538 \\
\hline TAS & 174348 & 17539 & 20108 & 16491 & 10287 & 7281 & 246054 \\
\hline NT & 115848 & 977 & 363 & 1118 & 2307 & 3172 & 123785 \\
\hline ACT & 353801 & 819 & 365 & 304 & 809 & 490 & 356588 \\
\hline Grand Total & 13779869 & 344265 & 416191 & 481500 & 558439 & 613641 & 16193905 \\
\hline
\end{tabular}

The resulting maps show, with the highest available granularity, the areas with high risk of oral cellulitis. This localisation of high risk areas could assist health authorities in identifying the most appropriate locations of future dental centres, as well as School Dental Services (SDS) in those areas, to pre-emptively reduce cases of cellulitis though more robust primary health initiatives in these areas of risk.

This audit found a very high proportion of the population at very high risk in rural and remote Northern Territory. This is not surprising as in the Northern Territory around $30 \%$ of population are Aboriginal and Torres Strait Islander people [8]. 
Table 3. Cumulative percentage of population belonging to risk categories 4 and 5 (high risk and very high risk) according to distance for all States and Territories in Australia by distance from GPO.

\begin{tabular}{|c|c|c|c|c|c|c|c|c|}
\hline \multirow[t]{2}{*}{ State } & \multicolumn{8}{|c|}{ Distance from centre of capital city (GPO) in $\mathrm{km}$} \\
\hline & $<02$ & $<05$ & $<10$ & $<20$ & $<40$ & $<60$ & $<80$ & $<100$ \\
\hline NSW & 0.79 & 1.09 & 3.04 & 24.51 & 63.06 & 80.00 & 89.67 & 100.00 \\
\hline VIC & 0.34 & 3.18 & 5.98 & 40.06 & 77.39 & 90.25 & 97.49 & 100.00 \\
\hline QLD & 0.00 & 1.17 & 2.84 & 18.00 & 68.42 & 80.05 & 94.33 & 100.00 \\
\hline SA & 0.00 & 2.23 & 28.12 & 62.34 & 92.88 & 93.74 & 98.17 & 100.00 \\
\hline WA & 0.00 & 0.91 & 15.08 & 51.49 & 80.30 & 91.16 & 96.23 & 100.00 \\
\hline TAS & 0.00 & 2.40 & 29.11 & 61.53 & 77.90 & 87.04 & 94.16 & 100.00 \\
\hline NT & 0.00 & 0.00 & 15.93 & 56.75 & 56.75 & 56.75 & 100.00 & 100.00 \\
\hline ACT & 100.00 & 100.00 & 100.00 & 100.00 & 100.00 & 100.00 & 100.00 & 100.00 \\
\hline
\end{tabular}

Furthermore, $43.2 \%$ of Australian Indigenous population live in outer regional, remote and very remote areas, as opposed to $10.4 \%$ of non-Indigenous population [8].

Another finding was the low number of population at risk of oral cellulitis in proximity to the GPO of capital cities, especially for Sydney, Melbourne and Brisbane, where the risk was significantly very low within $10 \mathrm{~km}$ from the core of the city. This may be an indicator of people of relative high socioeconomic status living in the inner-city centres, as well as the growing trend for more senior aged people to take-up apartment living in these areas, which changes the relative population risk for conditions such as oral cellulitis.

The analysis used poverty, age and indigenous status to develop the risk locator indicator. Oral infections have been reported to be of higher incidence it the poorest population groups of the society in the UK [13], the US [14], India [15] and Australia [7]. A 2014 US study [16] on oral cellulitis and Ludwig's Angina found higher rates of admission to hospital at nonwhite (40\%) and found age and insurance status to be factors associated with hospital admissions. Those results may be comparable to the trends used in this research as in Australia, 3\% of the population are Aboriginal and Torres Strait Islanders [8], who are reported to suffer from low level of dental health [17] and are generally more prone to be admitted to hospital [18].

GIS has been previously used to study geographic access to dental services [19] and to map the incidence of dental conditions [12]. However, the application of computer-based GIS technique for risk location of sporadic dental condition used in this model could be useful for risk assessment of other dental and medical conditions.

One interesting aspect of our study was the pooling of the hospitalisation data for 10 years, which may be considered a relatively long period. However, this is not uncommon in similar conditions [15] and could be further justified in this sporadic condition by the low annual incidence of cases.

The use of hospitalisation data from one State (Western Australia) as a representative sample for national model extrapolation could be considered a limitation of this study. Western Australia is the largest state in Australia by area with a diverse population of over 2.5 million people (being a $10-15 \%$ of the national population). The extrapolation of Western Australian data nationwide has been previously used $[12,20]$ as the hospitalisation data (poverty, Indigenous status) are not openly accessible in Australia on a national level. Furthermore, estimating nationwide hospitalisation trends based on a representative sample is commonly used practice $[13,15,21]$. 


\section{CONCLUSION}

In conclusion, this innovative method has provided a basis for examining the risk of cellulitis across a nation. Oral cellulitis was examined and specific areas of relative risk were identified. These types of approaches provide an evidence-based systematic approach to targeting primary care (and prevention) to specific communities to reduce the substantial burden to society that cases of high risk sporadic conditions incur.

\section{DECLARATION OF INTEREST}

The authors report no conflicts of interest. The authors alone are responsible with the content of this article.

\section{REFERENCES}

1. Dicker RC, Coronado F, Koo D, Parrish RG. Principles of epidemiology in public health practice; an introduction to applied epidemiology and biostatistics. $3^{\text {rd }}$ Ed. Centers for Disease Control and Prevention; 2006.

2. Luffman IE. Geographic and Socioeconomic Risk Factors for Sporadic Cryptosdporidiosis and E. coli infection in East Tennessee. [dissertation on the internet] University of Tennessee; 2013. Available from: http://trace.tennessee.edu/utk graddiss/2452

3. Bridgeman A, Wiesenfeld D, Hellyar A, Sheldon W. Major maxillofacial infections: An evaluation of 107 cases. Aust Dent J. 1995;40(5):281-288.

4. Huang TT, Liu TC, Chen PR, Tseng FY, Yeh TH, Chen YS. Deep neck infection: analysis of 185 cases. Head Neck 2004;26(10):854-60.

5. Zaleckas L, Rasteniene R, Rimkuviene J, Seselgyte R. Retrospective analysis of cellulitis of the floor of the mouth. Stomatologija. 2010; 12(1):23-27.

6. Greenberg SL, Huang J, Chang RS, Ananda SN. Surgical management of Ludwig's angina. ANZ J Surg. 2007; 77(7): 540-543.

7. Anjrini AA, Kruger E, Tennant M. A 10-year retrospective analysis of hospitalisation for oral cellulitis in Australia: the poor suffer at 30 times the rate of the wealthy. Faculty Dent J. 2014;5(1):8-13.

8. Australian Bureau of Statistics. Available from www.abs.gov.au

9. Slade G, Spencer A, Roberts-Thomson K. Australia's dental generations: the national survey of adult oral health 2004-06 Canberra: Australian institute of health and welfare; 2007. Available from: http://www.aihw.gov.au/publication-detail/?id=6442467953.

10. Hospital Morbidity Data System reference manual. Department of Health, Government of Western Australia; $2014 . \quad$ Available from: http://www.health.wa.gov.au/healthdata/docs/Hospital_Morbidity_Data_System_Reference_Manual.pdf

11. The International Classification of Diseases and Related Health Problems, 11th Revision, Australian Modification (ICD-10 AM). National Centre for Classification of Health: Lidcombe, Australia; 2000.

12. George R, Tennant M, Kruger E. Hospitalisations for removal of impacted teeth in Australia: A national geographic modeling approach. Rural and Remote Health. 2012;12(4): 2240.

13. Moles DR. Epidemic of dental abscesses?: Dental abscesses have increased most among poorer people. BMJ. 2008;336(7657):1323.

14. Nalliah RP, Allareddy V, Elangovan S, Karimbux N, Lee MK, Gajendrareddy P, et al. Hospital emergency department visits attributed to pulpal and periapical disease in the United States in 2006. J Endod. 2011;37(1):6-9.

15. Agarwal AK, Sethi A, Sethi D, Mrig S, Chopra S. Role of socioeconomic factors in deep neck abscess: A prospective study of 120 patients. Br J Oral Maxillofac Surg. 2007;45(7):553-5.

16. Allareddy V, Rampa S, Nalliah RP. Allareddy V. Longitudinal discharge trends and outcomes after hospitalization for mouth cellulitis and Ludwig angina. Oral Surg Oral Med Oral Pathol Oral Radiol. 2014;118(5):524-31.

17. Oral health of Aboriginal and Torres Strait Islander children. AIHW cat. no. DEN 167. Canberra: Australian Institute of Health and Welfare; 2007.

18. Aboriginal and Torres Strait Islander health performance framework 2014 report: detailed analyses. Canberra: Australian Institute of Health and Welfare; 2015. 
19. Dudko, Y., Kruger, E., Tennant, M. Geographic distribution of point-in-time access to subsidised dental services in Western Australia. Australian Journal of Primary Health. 2016;22(6):569-575.

20. Anjrini AA, Kruger E, Tennant M. Cost effectiveness modelling of a 'watchful monitoring strategy' for impacted third molars vs prophylactic removal under GA: an Australian perspective. Br Dent J. 2015;219(1):19-23.

21. Nalliah RP, Lee MK, Rampa S, Whitcomb M, Allareddy V, Allareddy V .Hospital-based ED visits with dental conditions among geriatric patients. J Mass Dent Soc. 2013;62(2):24-8.

License Information: This work is licensed under a Creative Commons Attribution 